\title{
LiDAR Helps Differentiate Stand Health and Productivity Levels within a Northern Hardwood Forest
}

\author{
Christopher F. Hansen', Paul G. Schaberg2*, Allan M. Strong1, Shelly A. Rayback ${ }^{3}$, Gary J. Hawley ${ }^{1}$ \\ ${ }^{1}$ Rubenstein School of Environment and Natural Resources, The University of Vermont, Burlington, VT, USA \\ ${ }^{2}$ USDA Forest Service, Northern Research Station, Burlington, VT, USA \\ ${ }^{3}$ Geography Department, The University of Vermont, Burlington, VT, USA \\ Email: ^Paul.Schaberg@usda.gov
}

How to cite this paper: Hansen, C. F., Schaberg, P. G., Strong, A. M., Rayback, S. A., \& Hawley, G. J. (2020). LiDAR Helps Differentiate Stand Health and Productivity Levels within a Northern Hardwood Forest. Open Journal of Forestry, 10, 66-80. https://doi.org/10.4236/ojf.2020.101006

Received: November 16, 2019

Accepted: December 22, 2019

Published: December 25, 2019

Copyright $\odot 2020$ by author(s) and Scientific Research Publishing Inc. This work is licensed under the Creative Commons Attribution International License (CC BY 4.0).

http://creativecommons.org/licenses/by/4.0/

\begin{abstract}
Light detection and ranging (LiDAR) data can provide detailed information about three-dimensional forest structure. However, links between forest structure and tree function have not been fully evaluated using LiDAR. We assessed the relationship of LiDAR-derived structural categories to tree health and productivity on 36 hardwood plots at the Hubbard Brook Experimental Forest, New Hampshire, USA. We established nine plot replicates for each of four LiDAR-based vegetation categories: 1 ) high crown and high understory closure; 2) high crown and low understory closure; 3) low crown and high understory closure; and 4) low crown and low understory closure. Ground-based measures of canopy structure, site, stand and individual tree measures were collected on plots during summer 2012. Significant differences among LiDAR categories were found for several response variables. Lower basal area increment for sugar maple (Acer saccharum), decreased foliar nutrition for yellow birch (Betula alleghaniensis), and lower overall crown health were all associated with high understory closure provided that overstory closure was also high. These results suggest that LiDAR measures can be used to assess competitive interactions between overstory and understory vegetation, and that LiDAR shows promise for identifying stands with reduced health and productivity due to factors such as competition or overstocking.
\end{abstract}

\section{Keywords}

Basal Area Increment, Crown Health, Foliar Nutrition, Tree Function, Tree Mortality 


\section{Introduction}

Managers and ecologists must develop cost-effective techniques to evaluate fundamental forest attributes that influence forest health and productivity, such as stand structure and complexity, and canopy closure. This is especially critical in the face of climate, environmental, and land-use changes that may alter the structure and function of forest systems. Light detection and ranging (LiDAR) remote sensing is a technique that may be useful for evaluating such attributes. LiDAR technology can be used to map vegetation structure in three dimensions, as well as record spectral intensity at landscape scales at relatively low costs compared to field-based measures (Lefsky et al., 2002; Sherrill et al., 2008; Luo et al., 2017).

The relationship of LiDAR to forest structure and function has only recently been assessed, with relatively few studies evaluating the relationship between LiDAR and specific measures of stand- and tree-based health and productivity. For example, Vitousek et al. (2009) evaluated the relationship of LiDAR-derived canopy vertical structure to remotely sensed measures of foliar chemistry and found clear relationships between canopy height and nitrogen $(\mathrm{N})$ concentrations. Other studies have utilized LiDAR to quantify forest structure and canopy functional traits (i.e., normalized difference vegetation index-NDVI) across elevation gradients (Asner et al., 2014), as well as relating LiDAR-derived gap frequency and forest structure to edaphic and geological patterns (Higgins et al., 2015). These studies evaluated LiDAR at broad landscape-scales, with no ground-based measures for direct comparisons. By contrast, Gökkaya et al. (2015) evaluated the utility of LiDAR in conjunction with spaceborne imaging spectroscopy in predicting ground-based measures of foliar macronutrients at the canopy level in mixed wood boreal forests. Their analysis found that the inclusion of LiDAR data with imaging spectroscopy significantly improved prediction accuracy of canopy macronutrients. They identified crown closure and canopy height as being the structural metrics most important in predicting canopy macronutrient concentrations. Similarly, in forests characterized by high structural heterogeneity, Ewald et al. (2018) also compared ground-based measures of $\mathrm{N}$ and phosphorus to remotely-sensed data, finding that LiDAR-derived variables improved model predictions from imaging spectroscopy alone.

Our research was (originally) designed (and scaled) to determine the relationship between high-resolution LiDAR and various ecosystem processes, including the abundance and diversity of arthropod and avian communities (Hansen, 2015). However, we also added plot-based measures to assess the relationship of LiDAR to tree health and productivity, with a particular emphasis on measures of tree function and health. We hypothesized that LiDAR can be used to quantify structural characteristics that are either the cause (e.g., overcrowding) or the consequence (e.g., greater crown thinning or tree mortality) of tree health and productivity issues. Therefore, LiDAR data should reflect components of tree-based measures that are influenced by forest structure and vegeta- 
tion density (e.g., competitive interactions among canopy strata for limited resources), which if verified, would support the use of LiDAR to generate proxy measures of forest health and productivity. The resulting analysis provides the first evaluation of the relationship between forest structure derived from LiDAR and the health and productivity of northern hardwood trees.

\section{Methods}

\subsection{Study Site, LiDAR Processing and Field Plot Selection}

This research was conducted at the Hubbard Brook Experimental Forest (HBEF) in Thornton, New Hampshire, USA ( $43^{\circ} 56^{\prime} \mathrm{N}, 71^{\circ} 45^{\prime} \mathrm{W}$; Figure 1). Elevations at HBEF range from 222 to $1015 \mathrm{~m}$, and forests below $750 \mathrm{~m}$ are dominated by northern hardwood species-primarily sugar maple (Acer saccharum Marsh.), American beech (Fagus grandifolia Ehrh.), and yellow birch (Betula alleghaniensis Britton).

High-resolution discrete return LiDAR data (flown leaf-on, September 1, 2009) were acquired for HBEF. These data were originally collected by the Canaan Valley Institute, West Virginia, for the University of Maryland, Department of Geography using an Optech ALTM 3100 flown at an altitude of approximately $1065 \mathrm{~m}$ above ground level (AGL). These data were received in raw (LAS 1.0) point cloud format with no associated surface models. Using Quick

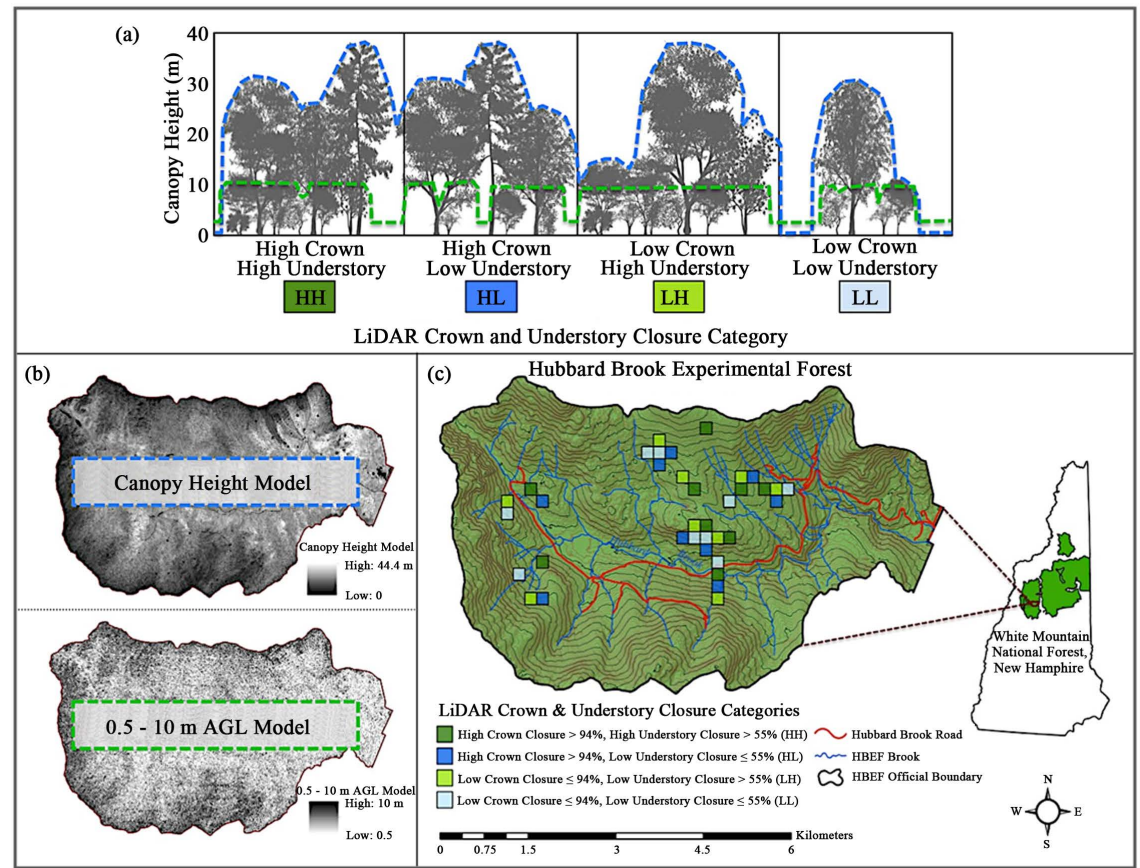

Figure 1. Study site and plot selection: (a) LiDAR crown and understory closure categories, (b) canopy height (nDSM) and 0.5 - 10 m AGL surface models, and (c) Hubbard Brook Experimental Forest, NH, USA - showing the 36, $200 \mathrm{~m} \times 200 \mathrm{~m}$ blocks. LiDAR surface models were derived from LiDAR point cloud data acquired for the Hubbard Brook Experimental Forest and originally collected by the Canaan Valley Institute, West Virginia, for the University of Maryland, Department of Geography. 
Terrain Modeler (Applied Imagery, Inc., Silver Spring, MD) and ERDAS Imagine (Intergraph Corporation, Inc., Madison, AL), we transformed LiDAR point cloud data into a normalized digital surface model (nDSM) to represent canopy height, a digital elevation model (DEM) to represent ground elevation, and a 0.5 - $10 \mathrm{~m}$ AGL surface model to represent the presence or absence of vegetation within the canopy's understory vertical plane.

Un-adjustable variations in LiDAR data involving the overlap of adjacent flight lines necessitated the conversion of raw LiDAR point clouds into surface models from which canopy and understory closure categories were created. We used eCognition, an object-oriented segmentation software (Trimble Geospatial, Inc., Westminster, CO), to identify two understory closure categories (high understory [55\% - 78.15\%] and low understory [43\% - 54.99\%] vegetation closure in the 0.5 - $10 \mathrm{~m}$ AGL class) and two crown closure categories (high crown closure [94\% - 98.09\%] and low crown closure [89.89\% - 93.99\%]). Canopy and understory categories were operationally defined to create breakpoints that divided the forest area assessed into two equal-sized groups per canopy strata. This resulted in four combinations of understory and crown closure categories: 1) high crown closure and high understory closure (hereafter referred to as $\mathrm{HH}$ ), 2) high crown closure and low understory closure (HL), 3) low crown closure and high understory closure (LH), and 4) low crown closure and low understory closure (LL) (Figure 1).

LiDAR-derived surface models were used in conjunction with pre-existing geospatial vector data (HBEF data archives-http://data.hubbardbrook.org/gis/) to identify areas of deciduous and mixed deciduous forest types within an elevation threshold of roughly $400-800 \mathrm{~m}$. A $200 \mathrm{~m} \times 200 \mathrm{~m}$ grid was placed over the resultant area to represent 4 ha sampling blocks for potential use. This block size was chosen because it approximated the territory size of black-throated blue warblers (Setophaga caerulescens) (Holmes et al., 2005), as one component of the broader study was to relate LiDAR data to avian habitat. Sampling blocks were then randomly selected based on the four LiDAR-derived canopy structure classifications, with nine replicates containing each of the four categories located in close proximity to account for any spatial clustering that might affect response variables-resulting in a total of $36,200 \mathrm{~m} \times 200 \mathrm{~m}$ blocks (Figure 1).

\subsection{Crown Health and Basal Area}

Within each of these blocks, we established a $50 \mathrm{~m}$ fixed radius plot that followed the standard design and protocols of the Forest Inventory and Analysis (FIA) program, including vegetation inventories on plots, subplots and micro-plots (Bechtold \& Scott, 2005). For all inventories, canopy health was assessed via crown vigor index, and percent branch dieback measures were estimated according to the methods of the North America Maple Project (Cooke et al., 1996). Crown vigor index employs a 1 - 5 scale, where ratings range from vigorous crowns (1) to dead crowns (5). Percent branch dieback was estimated using a 12-class system. Basal area (BA) per hectare was calculated for both live 
(2.5 - $12.5 \mathrm{~cm}$ diameter breast height (DBH) on micro-plots) and dead trees $(>12.5 \mathrm{~cm} \mathrm{DBH}$ on subplots) according to FIA protocol. All field-based data were collected during summer and fall 2012.

\subsection{Basal Area Increment}

At the plot level, five dominant or co-dominant sugar maple and five dominant or co-dominant yellow birch trees were selected for intensive tree-based measures. American beech was not selected due to the confounding influence that beech bark disease has had on the health and productivity of this species (Halman et al., 2014). Diameter at breast height (DBH) and visual assessments of canopy health were quantified, and xylem increment cores were obtained for each tree. Two increment cores were collected at $\mathrm{DBH}$ for each tree using a 5 $\mathrm{mm}$ increment borer to estimated tree age and assess annual growth. Cores were prepared using standard dendrochronological techniques (Stokes \& Smiley, 1968) and crossdated visually using the methods of Yamaguchi (1991). Tree rings were microscopically measured $(0.001 \mathrm{~mm}$ resolution using a Velmex sliding stage unit [Velmex Inc., Bloomfield, NY] with Measure J2X software [VoorTech Consulting, Holderness, $\mathrm{NH}$ ]) and statistically crossdated using the program COFECHA (Holmes, 1983). Chronology statistics (i.e., series intercorrelation, autocorrelation, and average mean sensitivity) were obtained from COFECHA by plot and species and used to calculate the expressed population signal (EPS; Wigley et al., 1984). To maximize the length of our dataset chronologies, we used an EPS value of 0.80 to achieve a uniform sample chronology from 1950-2012 for both species and all plots (Hansen, 2015). Tree age at breast height was calculated using the maximum number of rings per tree if pith was evident or estimated per core using a pith indicator (Speer, 2010). For all trees, we were able to estimate age from at least one core.

Individual tree-ring width chronologies were converted to basal area increment (BAI) according to the methods of Speer (2010). Individual BAI chronologies were then averaged per plot by species to create plot means that could be related to other plot-based data. Sugar maple and yellow birch BAI measurements were evaluated in relation to LiDAR categories for multiple time periods: mean BAI for 2009 (the year of LiDAR collection), mean BAI for the 1970s (i.e., 1970-1979) and 2000-2012. The 1970s was the period of peak inputs of acidic deposition in the northeastern US prior to amendments to the US Clean Air Act (Driscoll et al., 2001) and have been identified as an important turning point in the trajectory of sugar maple BAI growth (Drohan et al., 2002). The time period 2000-2012 was assessed to evaluate LiDAR's relationship to current BAI growth as inputs of acid deposition have decreased.

\subsection{Foliar Nutrition}

Foliar cations were assessed on sunlit/upper canopy foliage collected using shotguns in early August 2012 (Huggett et al., 2007). Samples were collected from the five sugar maple and five yellow birch per plot sampled for other 
tree-based measures. Foliage was oven-dried at $55^{\circ} \mathrm{C}$ for two weeks and ground using a Wiley Mill with a $2 \mathrm{~mm}$ mesh. Ground foliage was then run through a series of nitric acid and hydrogen peroxide digestions (Huggett et al., 2007). Cation concentrations (calcium $(\mathrm{Ca})$, aluminum $(\mathrm{Al})$, potassium $(\mathrm{K}), \mathrm{P}$, manganese $(\mathrm{Mn})$, and magnesium $(\mathrm{Mg})$ ) were measured from the digested foliage using inductively coupled plasma atomic emission spectrometry (Perkin-Elmer Optima DV 3000; Perkin-Elmer, Norwalk, CT) and expressed as $\mathrm{mg} / \mathrm{kg}$. Percent foliar carbon (C) and $\mathrm{N}$ were also assessed for two randomly selected sugar maple and two yellow birch trees per plot using a CHN-CE440 element analyzer (Exeter Analytical, Inc. North Chelmsford, MA). Peach leaf standards (National Institute of Standards and Technology SRM 15547) and blanks were processed for analytical comparisons.

\subsection{Statistical Analyses}

Analysis of variance (ANOVA) was used to test for differences among LiDAR categories. When significant differences among LiDAR categories existed for response variable means, specific differences among means were assessed using Tukey HSD tests. Regression analyses were used to assess trajectories in growth through 1979 and after 1980-the approximate start of sugar maple decline at HBEF (Fahey et al., 2005; Juice et al., 2006). Analyses were performed using the statistical package JMP (SAS Institute, Inc., Cary, NC), with results being considered significantly different if $P \leq 0.05$, unless otherwise noted.

\section{Results and Discussion}

\subsection{LiDAR Assessments of Crown Condition, Tree Mortality and BAI Growth}

Percent branch dieback was significantly different among LiDAR categories, with $\mathrm{HH}$ and LL categories exhibiting greater dieback than the HL category (Table 1 ). Crown vigor index was only marginally different among LiDAR categories $(P \leq 0.10)$, with a trend for LiDAR categories with high understory closure having a greater crown vigor index (poorer condition) regardless of crown closure (Table 1$)$. Standing-dead basal area was also marginally different $(P \leq$ 0.10 ) among LiDAR categories, with a tendency for plots with HL closure to exhibit the least standing-dead basal area (Table 1). In comparison, basal area of live understory and intermediate trees (DBH $2.5-12.5 \mathrm{~cm})$ was significantly greater $(P \leq 0.05)$ on $\mathrm{HH}$ plots compared to all other LiDAR categories, with $\mathrm{LH}$ plots also exhibiting greater live basal area despite showing no statistical difference from HL and LL plots (Table 1).

Measures of BAI were significantly different among LiDAR categories for sugar maple but not yellow birch (Table 2). For 2009 (year of LiDAR), BAI growth for sugar maple in $\mathrm{HH}$ plots was significantly lower than maples in LL plots, with growth in HL and $\mathrm{LH}$ being intermediate. For the recent period (2000-2012), maple growth in $\mathrm{HH}$ plots was lower than growth on HL plots, 
Table 1. Mean $( \pm$ SE) plot level percent branch dieback and crown vigor index, micro-plot live basal area, and sub-plot standing dead basal area by LiDAR category, collected during 2012 at the Hubbard Brook Experimental Forest, NH, USA.

\begin{tabular}{|c|c|c|c|c|c|}
\hline & \multirow{4}{*}{ Significance } & \multicolumn{4}{|c|}{ LiDAR crown \& understory closure category } \\
\hline \multirow{3}{*}{ Response variable } & & High crown & High crown & Low crown & Low crown \\
\hline & & High understory & Low understory & High understory & Low understory \\
\hline & & $(\mathrm{HH})$ & (HL) & $(\mathrm{LH})$ & (LL) \\
\hline \multicolumn{6}{|l|}{ Decline } \\
\hline$\%$ branch dieback & ** & $31.60 \pm 2.27^{\mathrm{a}}$ & $23.86 \pm 1.48^{\mathrm{b}}$ & $30.52 \pm 3.03^{\mathrm{ab}}$ & $31.17 \pm 2.12^{\mathrm{a}}$ \\
\hline Crown vigor index & * & $2.34 \pm 0.09$ & $1.97 \pm 0.07$ & $2.27 \pm 0.16$ & $2.22 \pm 0.10$ \\
\hline \multicolumn{6}{|l|}{$\underline{\text { Basal area }\left(\mathrm{m}^{2} / \mathrm{ha}\right)}$} \\
\hline Live $(2.5-12.5 \mathrm{~cm} \mathrm{DBH})$ & $* *$ & $4.33 \pm 0.64^{\mathrm{a}}$ & $2.27 \pm 0.56^{\mathrm{b}}$ & $2.48 \pm 0.50^{\mathrm{b}}$ & $2.33 \pm 0.64^{\mathrm{b}}$ \\
\hline Standing dead $(>12.5 \mathrm{~cm} \mathrm{DBH})$ & * & $6.26 \pm 1.30$ & $2.46 \pm 0.50$ & $5.13 \pm 1.03$ & $4.86 \pm 1.15$ \\
\hline
\end{tabular}

${ }^{\star *}$ and in bold $P \leq 0.05,{ }^{\star} P \leq 0.10$. Means $( \pm \mathrm{SE})$ with differing letters are statistically significantly different based on Tukey HSD tests.

Table 2. Mean $\left( \pm\right.$ SE) basal area increment $\left(\mathrm{cm}^{2}\right)$ for sugar maple and yellow birch trees by LiDAR category collected at the Hubbard Brook Experimental Forest, NH, USA.

\begin{tabular}{|c|c|c|c|c|c|}
\hline \multirow{4}{*}{ Response variable } & \multirow{4}{*}{ Significance } & \multicolumn{4}{|c|}{ LiDAR crown \& understory closure category } \\
\hline & & High crown & High crown & Low crown & Low crown \\
\hline & & High understory & Low understory & High understory & Low understory \\
\hline & & $(\mathrm{HH})$ & (HL) & $(\mathrm{LH})$ & (LL) \\
\hline \multicolumn{6}{|l|}{ Basal area increment $\left(\mathrm{cm}^{2}\right)$} \\
\hline \multicolumn{6}{|l|}{ Sugar Maple: } \\
\hline 2000-2012 & $* *$ & $7.05 \pm 1.58^{\mathrm{b}}$ & $11.09 \pm 0.96^{\mathrm{a}}$ & $10.92 \pm 1.58^{\mathrm{ab}}$ & $10.33 \pm 1.99^{\mathrm{ab}}$ \\
\hline 2009 (year of LiDAR acquisition) & ** & $7.73 \pm 1.74^{\mathrm{b}}$ & $11.69 \pm 0.98^{\mathrm{ab}}$ & $11.41 \pm 1.42^{\mathrm{ab}}$ & $12.44 \pm 2.66^{\mathrm{a}}$ \\
\hline 1970’s (1970-1979) & $* *$ & $11.05 \pm 1.44^{\mathrm{b}}$ & $18.50 \pm 2.66^{\mathrm{a}}$ & $18.44 \pm 0.97^{\mathrm{a}}$ & $15.45 \pm 1.72^{\mathrm{ab}}$ \\
\hline \multicolumn{6}{|l|}{ Yellow Birch: } \\
\hline $2000-2012$ & NS & $10.93 \pm 1.44$ & $10.99 \pm 1.42$ & $12.01 \pm 1.64$ & $11.37 \pm 0.59$ \\
\hline 2009 (year of LiDAR acquisition) & NS & $15.13 \pm 2.20$ & $14.36 \pm 1.38$ & $15.56 \pm 2.36$ & $14.86 \pm 0.93$ \\
\hline 1970’s (1970-1979) & NS & $12.24 \pm 1.24$ & $15.02 \pm 1.94$ & $14.21 \pm 2.28$ & $13.50 \pm 1.54$ \\
\hline
\end{tabular}

**and in bold $P \leq 0.05$, "NS" denotes not significant. Means $( \pm \mathrm{SE})$ with differing letters are statistically significantly different based on Tukey HSD tests.

with growth on LH and LL plots being intermediate (Table 2). In addition, sugar maple BAI growth for the 1970s was significantly lower on HH plots compared to HL and LH plots, with LL plots being intermediate. Growth trajectories over time also diverged among maples on $\mathrm{HH}$ versus $\mathrm{HL}$ plots. Maples on $\mathrm{HH}$ plots showed lower and stable growth before 1980 whereas maples on HL plots had greater and increasing growth during this period (Figure 2(a)). After 1980, the growth of maples on both $\mathrm{HH}$ and HL plots declined, though this reduction was more dramatic on HL plots (Figure 2(a)). There was a tendency for BAI to be lower for yellow birch on $\mathrm{HH}$ compared to HL plots (Figure 2(b)), but differences among means were not significant $(P=0.4687)$. Although maple BAI 


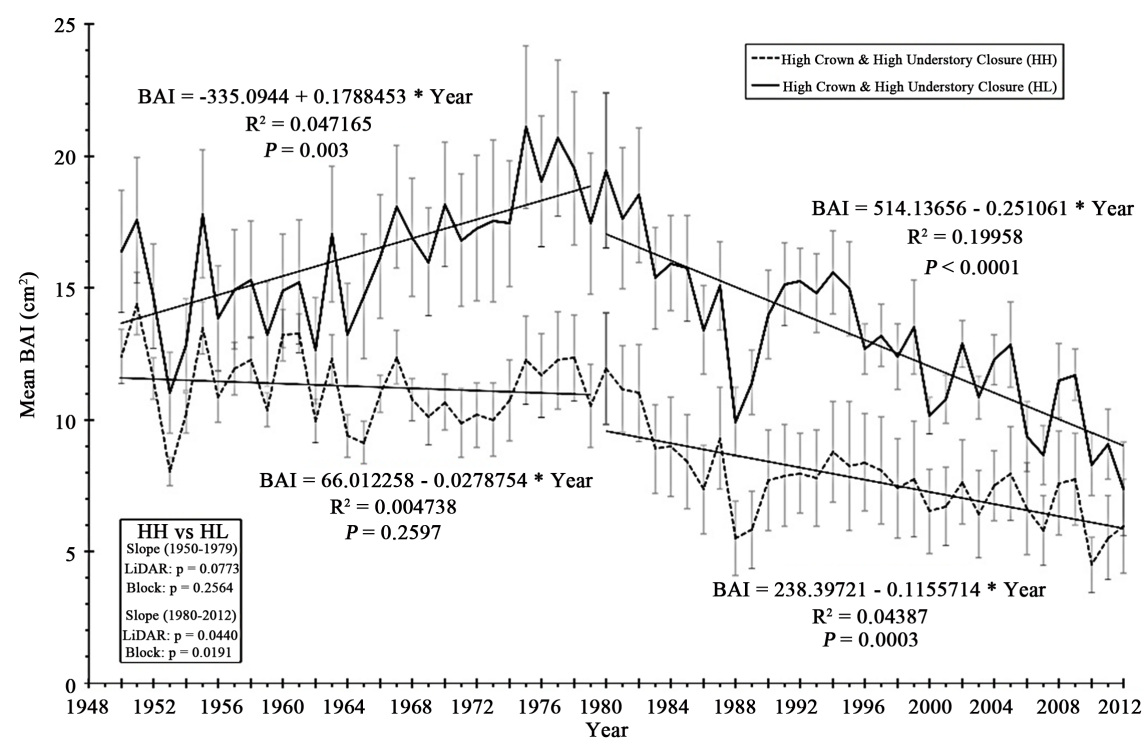

(a)

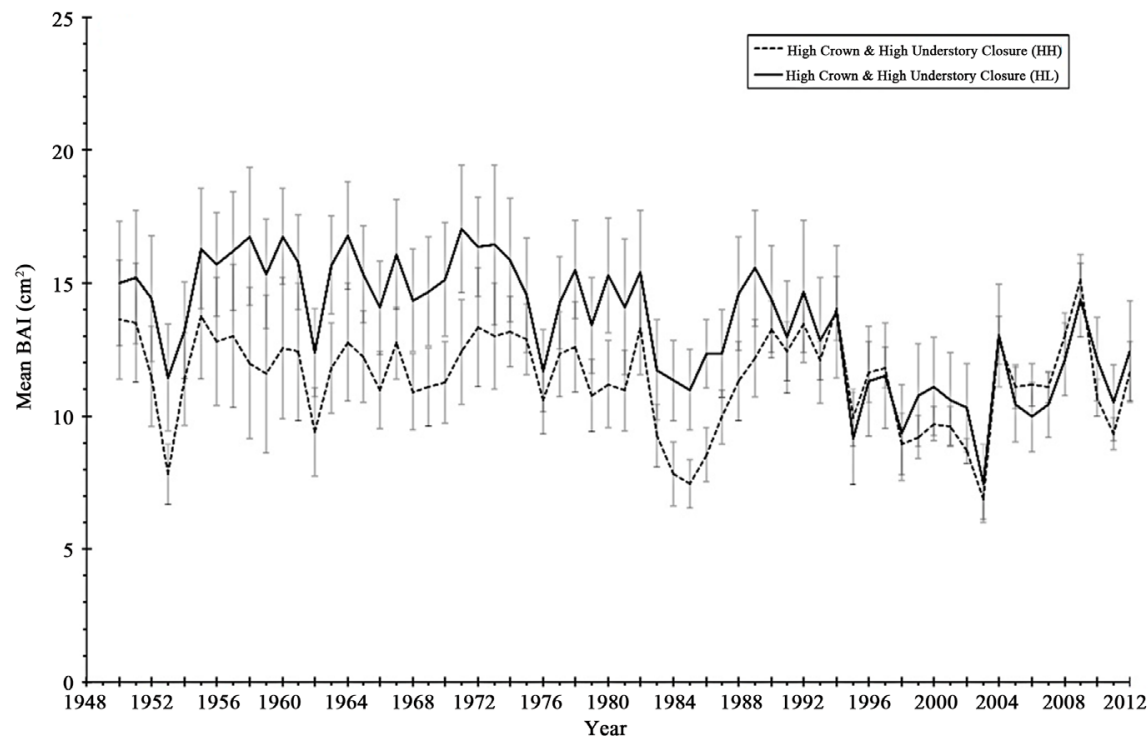

(b)

Figure 2. Mean basal area increment (BAI; \pm SE) for (a) sugar maple and (b) yellow birch trees on $\mathrm{HH}$ and HL LiDAR plots at the Hubbard Brook Experimental Forest, NH, USA. BAI was significantly different between $\mathrm{HH}$ and HL plots over the length of the chronology for sugar maple $(P=0.0064)$ but not for yellow birch trees $(P=0.4687)$. Regression equations are listed for sugar maple growth trajectories before and after 1980, approximately when decline began (Fahey et al., 2005; Juice et al., 2006). P-values indicate whether regressions slopes are significantly different from zero.

differed among LiDAR categories, estimated tree age did not differ among LiDAR groups for either sugar maple $(P>0.10)$ or yellow birch $(P>0.22)$, and tree ages for the $\mathrm{HH}$ and HL categories were nearly identical (Hansen, 2015).

Overall, $\mathrm{HH}$ plots exhibited significantly greater percent dieback and tended to have poor crown vigor and greater standing dead basal area, as well as greater live basal area for trees $2.5-12.5 \mathrm{~cm} \mathrm{DBH}$, than HL plots (Table 1). LiDAR cat- 
egories also showed utility in differentiating annual BAI growth for sugar maple. In two of the three time periods assessed, differences in sugar maple growth mirrored general trends in crown condition and standing dead basal area; growth was significantly lower in HH plots compared to HL plots, with LH and LL plots generally being intermediate (Table 2).

Because $\mathrm{HH}$ plots had the greatest crown closure and understory density, reduced tree performance in these plots likely reflects the consequences of competition for some limiting resource(s). In particular, the lower health (Table 1) and growth (Table 2) of sugar maple in HH compared to HL plots may indicate that, at least when canopy closure is high, added competition from understory vegetation may reduce sugar maple vigor and productivity. On our plots, four woody species dominated the understory: Fagus grandifolia, Viburnum alnifolium, Acer pensylvanicum and Acer saccharum. All had average densities over 10,000 stems/ha (Hansen, 2015). Competition between canopy and understory vegetation can have a meaningful influence on plant systems (Woods, 1984), including the reduced growth of overstory trees (Busse et al., 1996). Indeed, this concept of competitive interactions between overstory and understory trees and shrubs is one reason why silvicultural practices such as thinning-from-below (Barnes et al., 1997) and prescribed burning (Elliott et al., 1999) are used to control woody understory vegetation.

Competition for light is unlikely affecting tree growth because greater understory plant densities would not increase competition for light with overtopping canopy trees. Furthermore, even though sugar maples are known to be drought sensitive (Horsley et al., 2002), it seems unlikely that competition for water would be a dominant factor driving competitive interactions here because measured soil moisture levels did not differ among the LiDAR categories (Hansen, 2015) and because the northeastern US has been in a pluvial period since the end of a regional drought in the 1960s (Pederson et al., 2013). Indeed, differences in sugar maple BAI between $\mathrm{HH}$ and HL categories were comparatively low during the 1960s, but increased thereafter (Figure 2(a)). Thus, several lines of evidence suggest that water should be generally abundant and not a factor limiting tree growth. By contrast, considering the well-established nutritional limitations of the northern hardwood forests of HBEF (Likens et al., 1998), we propose that competition for nutrients between understory and overstory plants may be responsible for the differences in health and productivity we detected among LiDAR plots. Belowground competition from shrub roots may be most important in nutrient-poor sites (Montgomery et al., 2010), and Rolo et al. (2012) found that overstory trees growing with a shallow rooted shrub could also experience Ca limitations - a potential response with particular relevance for the Ca-limited forests of the HBEF (Likens et al., 1998).

\subsection{Foliar Nutrition}

No differences in foliar cation concentrations or percent $\mathrm{N}$ and $\mathrm{C}$ were found for sugar maple among LiDAR categories (Table 3). Nonetheless, foliar cation 
Table 3. Mean ( $\pm \mathrm{SE})$ foliar $\mathrm{Ca}, \mathrm{Mg}, \mathrm{Mn}, \mathrm{Al}$, and $\mathrm{Ca}: \mathrm{Al}$ molar ratio $\left(\mathrm{mg} \cdot \mathrm{kg}^{-1}\right)$ and percent $\mathrm{C}$ and $\mathrm{N}$ for sugar maple and yellow birch trees by LiDAR category collected at Hubbard Brook Experimental Forest, NH, USA.

\begin{tabular}{|c|c|c|c|c|c|}
\hline \multirow{4}{*}{$\begin{array}{l}\text { Foliar nutrition } \\
\quad\left(\mathrm{mg} \cdot \mathrm{kg}^{-1}\right)\end{array}$} & \multirow{4}{*}{ Significance } & \multicolumn{4}{|c|}{ LiDAR crown \& understory closure category } \\
\hline & & High crown & High crown & Low crown & Low crown \\
\hline & & High understory & Low understory & High understory & Low understory \\
\hline & & $(\mathrm{HH})$ & (HL) & $(\mathrm{LH})$ & (LL) \\
\hline \multicolumn{6}{|l|}{ Sugar maple: } \\
\hline $\mathrm{Ca}$ & NS & $4965.89 \pm 565.79$ & $5534.03 \pm 192.17$ & $5650.07 \pm 626.43$ & $5214.28 \pm 429.92$ \\
\hline$A l$ & NS & $69.85 \pm 10.95$ & $63.48 \pm 9.13$ & $70.85 \pm 11.66$ & $72.39 \pm 10.33$ \\
\hline$K$ & NS & $7470.56 \pm 366.76$ & $8152.25 \pm 481.53$ & $8311.45 \pm 452.42$ & $7911.42 \pm 454.05$ \\
\hline$P$ & NS & $1455.37 \pm 175.26$ & $1546.09 \pm 222.51$ & $1347.03 \pm 136.33$ & $1598.29 \pm 215.66$ \\
\hline$M g$ & NS & $976.82 \pm 107.59$ & $1045.7 \pm 50.46$ & $1035.3 \pm 107.52$ & $972.79 \pm 89.55$ \\
\hline$M n$ & NS & $1307.39 \pm 192.33$ & $1020.60 \pm 104.65$ & $1324.35 \pm 169.05$ & $989.51 \pm 108.72$ \\
\hline Ca:Al Molar Ratio & NS & $55.71 \pm 8.91$ & $70.41 \pm 11.09$ & $70.14 \pm 18.9$ & $55.91 \pm 8.49$ \\
\hline$C(\%)$ & NS & $48.82 \pm 0.72$ & $48.32 \pm 0.50$ & $47.61 \pm 0.41$ & $47.59 \pm 0.45$ \\
\hline$N(\%)$ & NS & $2.45 \pm 0.08$ & $2.49 \pm 0.05$ & $2.50 \pm 0.08$ & $2.25 \pm 0.07$ \\
\hline \multicolumn{6}{|l|}{ Yellow birch: } \\
\hline $\mathrm{Ca}$ & ** & $7966.97 \pm 489.31^{b}$ & $10122.90 \pm 667.88^{\mathrm{a}}$ & $7969.18 \pm 384.25^{b}$ & $8757.82 \pm 472.02^{\mathrm{ab}}$ \\
\hline$A l$ & NS & $68.13 \pm 8.32$ & $59.01 \pm 9.34$ & $61.31 \pm 9.24$ & $51.73 \pm 6.93$ \\
\hline$K$ & NS & $9653.69 \pm 748.75$ & $11814.4 \pm 972.45$ & $11776.79 \pm 714.89$ & $11289.71 \pm 974.94$ \\
\hline$P$ & NS & $1425.87 \pm 108.95$ & $1479.61 \pm 79.13$ & $1291.43 \pm 80.48$ & $1729.22 \pm 226.74$ \\
\hline$M g$ & NS & $2347.36 \pm 140.4$ & $2479.96 \pm 132.97$ & $2197.16 \pm 88.13$ & $2323.18 \pm 125.26$ \\
\hline$M n$ & NS & $1794.31 \pm 259.1$ & $1727.24 \pm 200.49$ & $1522.94 \pm 251.59$ & $1322.55 \pm 126.98$ \\
\hline Ca:Al Molar Ratio & * & $85.06 \pm 8.35^{\mathrm{b}}$ & $132.98 \pm 16.67^{\mathrm{a}}$ & $101.31 \pm 13.83^{\mathrm{ab}}$ & $130.84 \pm 18.4^{\mathrm{ab}}$ \\
\hline$C(\%)$ & NS & $48.19 \pm 0.63$ & $47.67 \pm 0.49$ & $47.13 \pm 0.4$ & $47.61 \pm 0.67$ \\
\hline$N(\%)$ & NS & $2.86 \pm 0.06$ & $2.84 \pm 0.11$ & $2.91 \pm 0.09$ & $2.79 \pm 0.09$ \\
\hline
\end{tabular}

** and in bold $P \leq 0.05,{ }^{*} P \leq 0.10$, "NS" denotes not significant; Means ( $\left.\pm \mathrm{SE}\right)$ with differing letters are statistically significantly different based on a Tukey HSD test.

concentrations across LiDAR groups often deviated from levels considered healthy for sugar maple trees (Kolb \& McCormick, 1993). For example, Mg was lower and $\mathrm{Al}$ was greater than typical levels, whereas foliar Ca concentrations were below healthy levels in $\mathrm{HH}$ plots and slightly above these levels in other LiDAR categories. Furthermore, the molar ratios of Ca:Al were well below those reported for vigorous sugar maple trees. Long et al. (1997) suggested that anything less than a Ca:Al molar ratio of 110 was associated with sugar maple decline, whereas Ca:Al levels were well below 75 for the sugar maples that we assessed (Table 3). Data from ambient and cation-treated sites have established that these changes in soil cation availability have altered tree $\mathrm{Ca}$ and $\mathrm{Al}$ nutrition, and impaired the physiology and growth of sugar maple trees (e.g., Horsley et al., 2002; Huggett et al., 2007). We propose that the dominance of ac- 
id-induced leaching resulted in fairly uniform and marginally sufficient $\mathrm{Ca}$ and elevated $\mathrm{Al}$ foliar concentrations that overwhelmed variation among our LiDAR categories, but which predisposed maples to reduced growth after 1980 (Figure $2(\mathrm{a})$ ).

For yellow birch only, foliar $\mathrm{Ca}$ concentrations and $\mathrm{Ca}: \mathrm{Al}$ molar ratio differed significantly; HL plots exhibited significantly greater foliar Ca than $\mathrm{HH}$ and $\mathrm{LH}$ plots, with LL plots being intermediate, and Ca:Al molar ratios were significantly greater on HL plots compared to HH plots, with LH and LL being intermediate. To our knowledge, there are no published ranges for healthy foliar cation concentrations for yellow birch. However, comparison of our data (Table 3) to the means reported in the Northeastern Ecosystem Research Cooperative foliar chemistry database (NERC, 2016) indicated that the concentrations that we quantified were close to $(<1 \mathrm{SD}$ from) regional means reported for all cations and $\mathrm{C}$, with the exception of $\mathrm{K}, \mathrm{Al}$, and percent $\mathrm{N}$ (which were slightly $>1 \mathrm{SD}$ above regional means). Furthermore, yellow birch foliage generally accumulated greater concentrations of all cations other than $\mathrm{P}$ and $\mathrm{Al}$ than did sugar maple trees (Table 3). Similar to health and productivity measures, foliar Ca concentrations in yellow birch were significantly lower in HH plots than in HL plots, with concentrations in LH and LL plots tending to be intermediate (Table 3). This could indicate that in areas with high crown competition, yellow birch with less understory competition have greater access to Ca.

\section{Conclusion}

LiDAR has been shown to be a useful tool in assessing basic measures of forest structure, such as canopy height, basal area, and leaf area index (Næsset, 2007; Jensen et al., 2008; Pearse et al., 2017; Luo et al., 2017). However, the ability of LiDAR to bridge the gaps between forest canopy structure and tree health and productivity measures has only recently been evaluated, and principally in relation to canopy chemistry (e.g., Vitousek et al., 2009; Gökkaya et al., 2015; Ewald et al., 2018). Our results show the novel ability of LiDAR to assess stand condition and function via competition between overstory and understory vegetation. In our study, these differences were primarily detected for plots with closed canopies that varied in understory closure, suggesting that increased competition from understory plants reduced overstory vigor, sugar maple BAI growth, and yellow birch foliar Ca concentrations. However, at locations where other site and competitive factors influence stand structure and function, we expect that LiDAR estimates could be associated with an even broader range of stand- and tree-based measures of health and productivity. In addition, LiDAR continuous point cloud data had to be converted to categorical LiDAR classes, which undoubtedly simplified and minimized the informational content of estimated forest structure. Despite these limitations, LiDAR estimates were associated with various measures of forest health and productivity. The breadth and consistency of the relationships we found is testament to the strong predictive capacity of 
LiDAR-based measures of forest structure for elucidating associated patterns of tree function and incipient decline. Indeed, as forests face more biotic (e.g., invasive pests and pathogens) and abiotic (e.g., climate, pollutant and nutrient) stressors, an improved ability to quantify forest health and productivity remotely via technologies like LiDAR will likely have greater demand and utility.

\section{Acknowledgements}

We are grateful to all of those who provided technical assistance in the lab and in the field. They include, Sean MacFaden, Josh Halman, Paula Murakami, Ben Engel, Dan Hale, Ali Kosiba, Kindle Loomis, Allison Middleman, Allyson Makuch, Jarlath O’Neil-Dunne, Nick Rodenhouse, and Helen Yurchenco. This research relied heavily on the assistance of staff at HBEF, especially Ian Halm. This manuscript is a contribution of the Hubbard Brook Ecosystem Study. Hubbard Brook is part of the Long-Term Ecological Research (LTER) network, which is supported by the National Science Foundation. The Hubbard Brook Experimental Forest is operated and maintained by the USDA Forest Service, Northern Research Station, Newtown Square, PA. This research was supported by funds provided by the Northeastern States Research Cooperative and the USDA CSREES McIntire-Stennis Forest Research Program.

\section{Conflicts of Interest}

The authors declare no conflicts of interest regarding the publication of this paper.

\section{References}

Asner, G. P., Martin, R. E., Knapp, D. E., Tupayachi, R., Sinca, F., \& Malhi, Y. (2014). Landscape-Scale Changes in Forest Structure and Functional Traits along an Andes-to-Amazon Elevation Gradient. Biogeosciences, 11, 843. https://doi.org/10.5194/bg-11-843-2014

Barnes, B. V., Zak, D. R., Denton, S. R., \& Spurr, S. H. (1997). Forest Ecology. New York: John Wiley and Sons.

Bechtold, W. A., \& Scott, C. T. (2005). The Forest Inventory and Analysis Plot Design. In The Enhanced Forest Inventory and Analysis Program-National Sampling Design and Estimation Procedures (pp. 27-42). General Technical Report SRS-GTR-80, Asheville, NC: USDA Forest Service, Southern Research Station.

Busse, M. D., Cochran, P. H., \& Barrett, J. W. (1996). Changes in Ponserosa Pine Site Productivity Following Removal of Understory Vegetation. Soil Science Society of America Journal, 60, 1614-1621. https://doi.org/10.2136/sssaj1996.03615995006000060004x

Cooke, E. R., Pendrel, B., Barnett, C., \& Allen, D. (1996). North American Maple Project Cooperative Field Manual. Upper Darby, PA: USDA Forest Service, Northeast Forest Experimental Station.

Driscoll, C. T., Lawrence, G. B., Bulger, A. J., Butler, T. J., Cronan, C. S., Eagar, C., Lambert, K. F., Likens, G. E., Stoddard, J. L., \& Weathers, K. C. (2001). Acidic Deposition in the Northeastern United States: Sources and Inputs, Ecosystem Effects, and Management Strategies. BioScience, 51, 180-198. 
https://doi.org/10.1641/0006-3568(2001)051[0180:ADITNU]2.0.CO;2

Drohan, P. J., Stout, S. L., \& Petersen, G. W. (2002). Sugar Maple (Acer saccharum Marsh.) Decline during 1979-1989 in Northern Pennsylvania. Forest, Ecology and Management, 170, 1-17. https://doi.org/10.1016/S0378-1127(01)00688-0

Elliott, K. J., Hendrick, R. L., Major, A. E., Voss, J. M., \& Swank, W. T. (1999). Vegetation Dynamics after a Prescribed Fire in the Southern Appalachians. Forest, Ecology and Management, 114, 199-213. https://doi.org/10.1016/S0378-1127(98)00351-X

Ewald, M., Aerts, R., Lenoir, J., Fassnacht, F. E., Nicolas, M., Skowronek, S., Van De Kerchove, R. et al. (2018). LiDAR Derived Forest Structure Data Improves Predictions of Canopy N and P Concentrations from Imaging Spectroscopy. Remote Sensing of Environment, 211, 13-25. https://doi.org/10.1016/j.rse.2018.03.038

Fahey, T. J., Siccama, T. G., Driscoll, C. T., Likens, G. E., Campbell, J., Johnson, C. E., Battles, J. J., Aber, J. D., Cole, J. J., Fisk, M. C., Groffman, P. M., Hamburg, S. P., Holmes, R. T., Swarz, P. A., \& Yani, R. D. (2005). The Biogeochemistry of Carbon at Hubbard Brook. Biogeochemistry, 75, 109-176.

https://doi.org/10.1007/s10533-004-6321-y

Gökkaya, K., Thomas, V., Noland, T. L., McCaughey, H., Morrison, I., \& Treitz, P. (2015). Prediction of Macronutrients at the Canopy Level Using Spaceborne Imaging Spectroscopy and LiDAR Data in a Mixed Wood Boreal Forest. Remote Sensing, 7, 9045-9069. https://doi.org/10.3390/rs70709045

Halman, J. M., Schaberg, P. G., Hawley, G. J., Hansen, C. F., \& Fahey, T. J. (2014). Differential Impacts of Calcium and Aluminum Treatments on Sugar Maple and American Beech Growth Dynamics. Canadian Journal of Forest Research, 45, 52-59. https://doi.org/10.1139/cjfr-2014-0250

Hansen, C. F. (2015). LiDAR Remote Sensing of Forest Canopy Structure: An Assessment of the Accuracy of LiDAR and Its Relationship to Higher Trophic Levels. M.Sc. Thesis, Burlington, VT: The University of Vermont, Rubenstein School of Environment and Natural Resources.

Higgins, M. A., Asner, G. P., Anderson, C. B., Martin, R. E., Knapp, D. E., Tupayachi, R., Perez, E., Elespuru, N., \& Alonso, A. (2015). Regional-Scale Drivers of Forest Structure and Function in Northwestern Amazonia. PLOS ONE, 10, e0119887. https://doi.org/10.1371/journal.pone.0119887

Holmes, R. L. (1983). Computer-Assisted Quality Control in Tree-Ring Dating and Measurement. Tree-Ring Bulletin, 43, 69-78.

Holmes, R. T., Rodenhouse, N. L., \& Sillett, T. S. (2005). Black-Throated Blue Warbler (Setophaga caerulescens). The Birds of North America, Cornell Lab of Ornithology.

http://bna.birds.cornell.edu/bna/species/087

https://doi.org/10.2173/bna.087

Horsley, S. B., Long, R. P., Bailey, S. W., Hallett, R. A., \& Wargo, P. M. (2002). Health of Eastern North American Sugar Maple Forests and Factors Affecting Decline. Northern Journal of Applied Forestry, 19, 34-44. https://doi.org/10.1093/njaf/19.1.34

Huggett, B. A., Schaberg, P. G., Hawley, G. J., \& Eagar, C. (2007). Long-Term Calcium Addition Increases Growth Release, Wound Closure, and Health of Sugar Maple (Acer saccharum) Trees at the Hubbard Brook Experimental Forest. Canadian Journal of Forest Research, 37, 1692-1700. https://doi.org/10.1139/X07-042

Jensen, J. L., Humes, R. K. S., Vierling, L. A., \& Hudak, A. T. (2008). Discrete Return Lidar-Based Prediction of Leaf Area Index in Two Conifer Forests. Remote Sensing of the Environment, 112, 3947-3957. https://doi.org/10.1016/j.rse.2008.07.001

Juice, S. M., Fahey, T. J., Siccama, T. G., Driscoll, C. T., Denny, E. G., Eagar, C., Cleavitt, 
N. L., Minocha, R., \& Richardson, A. D. (2006). Response of Sugar Maple to Calcium Addition to Northern Hardwood Forest. Ecology, 87, 1267-1280. https://doi.org/10.1890/0012-9658(2006)87[1267:ROSMTC]2.0.CO;2

Kolb, T., \& McCormick, L. (1993). Etiology of Sugar Maple Decline in Four Pennsylvania Stands. Canadian Journal of Forest Research, 23, 2395-2402. https://doi.org/10.1139/x93-296

Lefsky, M. A., Cohen, W. B., Parker, G. G., \& Harding, D. J. (2002). Lidar Remote Sensing for Ecosystem Studies. BioScience, 52, 19-30. https://doi.org/10.1641/0006-3568(2002)052[0019:LRSFES]2.0.CO;2

Likens, G., Driscoll, C., Buso, D., Siccama, T., Johnson, C., Lovett, G., Fahey, T., Reiners, W., Ryan, D., \& Martin, C. (1998). The Biogeochemistry of Calcium at Hubbard Brook. Biogeochemistry, 41, 89-173. https://doi.org/10.1023/A:1005984620681

Long, R. P., Horsley, S. B., \& Lilja, P. R. (1997). Impact of Forest Liming on Growth and Crown Vigor of Sugar Maple and Associated Hardwoods. Canadian Journal of Forest Research, 27, 1560-1573. https://doi.org/10.1139/x97-074

Luo, S., Chen, J. M., Wang, C., Gonsamo, A., Xi, X., Lin, Y., Qin, H. et al. (2017). Comparative Performances of Airborne LiDAR Height and Intensity Data for Leaf Area Index Estimation. IEEE Journal of Selected Topics in Applied Earth Observations and Remote Sensing, 11, 300-310. https://doi.org/10.1109/JSTARS.2017.2765890

Montgomery, R. A., Reich, P. B., \& Palik, B. J. (2010). Untangeling Positive and Negative Biotic Interactions: Views from Above and Below Ground in a Forest Ecosystem. Ecology, 91, 3641-3655. https://doi.org/10.1890/09-1663.1

Næsset, E. (2007). Airborne Laser Scanning as a Method in Operational Forest Inventory: Status of Accuracy Assessments Accomplished in Scandinavia. Scandinavian Journal of Forest Research, 22, 433-442. https://doi.org/10.1080/02827580701672147

NERC (2016). Foliar Chemistry On-Line Database of the Northeastern Ecosystem Research Cooperative. http://foliar.sr.unh.edu

Pearse, G. D., Morgenroth, J., Watt, M. S., \& Dash, J. P. (2017). Optimising Prediction of Forest Leaf Area Index from Discrete Airborne Lidar. Remote Sensing of Environment, 200, 220-239. https://doi.org/10.1016/j.rse.2017.08.002

Pederson, N., Bell, A. R., Cook, E. R., Lall, U., Devineni, N., Seager, R., Eggleston, K., \& Vranes, K. P. (2013). Is an Epic Pluvial Masking the Water Insecurity of the Greater New York City Region? Journal of Climate, 26, 1339-1354.

https://doi.org/10.1175/JCLI-D-11-00723.1

Rolo, V., López-Díaz, M. L., \& Moreno, G. (2012). Shrubs Affect Soil Nutrients Availability with Contrasting Consequences for Pasture Understory and Tree Overstory Production and Nutrient Status in Mediterranean Grazed Open Woodlands. Nutrient Cycling in Agroecosystems, 93, 89-102. https://doi.org/10.1007/s10705-012-9502-4

Sherrill, K. R., Lefsky, M. A., Bradford, J. B., \& Ryan, M. G. (2008). Forest Structure Estimation and Pattern Exploration from Discrete-Return Lidar in Subalpine Forests of the Central Rockies. Canadian Journal of Forest Research, 38, 2081-2096.

https://doi.org/10.1139/X08-059

Speer, J. H. (2010). Fundamentals of Tree-Ring Research. Tucson, AZ: The University of Arizona Press.

Stokes, M. A., \& Smiley, T. L. (1968). An Introduction to Tree-Ring Dating. Chicago, IL: University of Chicago Press.

Vitousek, P., Asner, G. P., Chadwick, O. A., \& Hotchkiss, S. (2009). Landscape-Level Variation in Forest Structure and Biogeochemistry across a Substrate Age Gradient in Hawaii. Ecology, 90, 3074-3086. https://doi.org/10.1890/08-0813.1 
Wigley, T., Briffa, K., \& Jones, P. (1984). On the Average Value of Correlated Time Series, with Applications in Dendroclimatology and Hydrometeorology. Journal of Climate and Applied Meteorology, 23, 201-213.

https://doi.org/10.1175/1520-0450(1984)023<0201:OTAVOC>2.0.CO;2

Woods, K. D. (1984). Patterns of Tree Replacement: Canopy Effects on Understory Pattern in Hemlock-Northern Hardwood Forests. Vegetation, 56, 87-107.

Yamaguchi, D. K. (1991). A Simple Method for Cross-Dating Increment cores from Living Trees. Canadian Journal of Forest Research, 21, 414-416.

https://doi.org/10.1139/x91-053 